\title{
Curiosity as a moderating variable between Impulsivity and Entrepreneurial Orientation
}

\author{
Joan Boada-Grau1, Mauricio Vallejo-Vélez², María José Serrano-Fernández ${ }^{1,3 *}$, José Carlos Sánchez-García ${ }^{4}$, \\ Maria Boada-Cuerva ${ }^{5}$, Jordi Assens-Serra ${ }^{6}$, and Andreu Vigil-Colet ${ }^{1}$ \\ 1 Faculty of Education Sciences and Psychology. Universitat Rovira i Virgili (URV), Tarragona (Spain). \\ 2 Faculty of Psychology. Universidad de Medellin (UDEM), Medellin (Colombia). \\ 3 Department of Education Sciences and Psychology. Universitat Oberta de Catalunya (UOC), Barcelona (Spain) \\ 4 Department of Psychology. Universidad de Salamanca (US AL), Salamanca (Spain) \\ 5 Faculty of Economics and Business. Universitat Rovira $i$ Virgili (URV), Reus (Spain) \\ $6 \mathrm{EADA}$, Business School (EADA), Barcelona (Spain).
}

\begin{abstract}
Título: La curiosidad como variable moderadora entre la Impulsividad y la Orientación Emprendedora.

Resumen: El objetivo del presente estudio es analizar si la curiosidad es una variable moderadora entre la Impulsividad y la Orientación Emprendedora. Se utiliza una muestra multiocupacional de 883 empleados españoles (49\% hombres, $51 \%$ mujeres), obtenidos mediante un muestreo no probabilístico. Se ha utilizado el programa SPSS 23.0. Se encontraron correlaciones estadísticamente significativas entre todas las variables de la investigación a excepción de la impulsividad Funcional. Finalmente, la evidencia empírica indica que la Curiosidad-D tiene un papel moderador entre la impulsividad Disfuncional y la Orientación Emprendedora mostrada, en el sentido de que la Curiosidad-D (entendida como una variable cuantitativa) afecta la intensidad de la relación entre la Impulsividad Disfuncional (variable predictora) y la Orientación Emprendedora (variable de criterio).

Palabras clave: Impulsividad. Curiosidad. Orientación emprendedora.
\end{abstract} Emprendeduría.

\section{Introduction}

Entrepreneurial Orientation has been associated with high performance in both organizations and at the individual level (Robinson \& Stubberud, 2014). Some of the characteristics commonly associated with it are competitive aggressiveness, autonomy, capacity for innovation, proactivity and willingness to take risks (Aljanabi, 2018; Bolton, 2012; Fillis \& Rentschler, 2010; Rauch et al., 2009; S. Robinson \& Stubberud, 2014)

Studying the relationship between Impulsivity and Entrepreneurial Orientation showed that sensation seeking and a lack of premeditation generally have a positive influence on entrepreneurship (Wiklund et al., 2017). These authors conclude that Impulsivity is positive for Entrepreneurial Orientation and that sensation seeking is related to curiosity and is intrinsic to motivation (Collins et al., 2004; Wismans et al., 2020; Zuckerman, 1994).

Robinson (2008) indicates that entrepreneurs need to be curious, feel challenged and, consequently, adapt to change, which drives them to be seekers of new opportunities. In addition, in an effort to understand the role played by curios-

\footnotetext{
* Correspondence address [Dirección para correspondencia]:

Dra. María-José Serrano-Fernández. Universitat Rovira i Virgili (URV)

Faculty of Education Sciences and Psychology. Campus Sescelades. Ctra

Valls, s/n, Tarragona 43007, Tarragona (Spain).

E-mail: mariajose.serrano@urv.cat

(Article received: 03-04-2020, revised: 02-12-2020, accepted: 11-01-2021)
}

Abstract: The objective of the present study is to analyze whether the variable Curiosity is a moderating variable between Impulsivity and Entrepreneurial Orientation. The multi-occupational sample of 883 Spanish and Colombian employees ( $49 \%$ men, $51 \%$ women) was obtained through non-probabilistic sampling. The data collected were processed with the SPSS 23.0 program. Statistically significant correlations were found among all the research variables except for Functional Impulsivity. Finally, empirical evidence indicates that Curiosity-D plays a moderating role between Dysfunctional Impulsivity and Entrepreneurial Orientation in the sense that Curiosity-D (understood as a quantitative variable) affects the intensity of the relationship between Dysfunctional Impulsivity (predictor variable) and Entrepreneurial Orientation (criterion variable).

Keywords: Impulsivity. Curiosity. Entrepreneurial Orientation. Entrepreneurialism.

ity in stimulating innovation and creativity in entrepreneurs, it is important to examine the lack of experience of business managers in decision-making in economies in transition. This paper studies the role played by curiosity as a mediating variable between Impulsivity and Entrepreneurial Orientation.

\section{Impulsivity}

The term Impulsivity is usually used to mean the tendency to respond in a hasty, abrupt or premature manner (Dickman, 1993). But a hasty response may or may not be adaptive to certain situations, so it is expected that a person who acts quickly does not take time to analyze the situation, for example in situations that involve having to make quick decisions before an imminent danger (Dickman, 2000). Thus impulsivity is a tendency to act with little foresight, and can be functional and dysfunctional (Dickman, 1990, 1993, 2000), which depends on its adaptive content. Dickman (1990) assumes that impulsivity is not always negative, but impulsive people tend to respond quickly and inaccurately, which can sometimes be a source of difficulties and at other times can be beneficial. This is why it has two different dimensions: functional impulsivity and dysfunctional impulsivity.

In relation to entrepreneurship, Wiklund, Yu, Tucker, and Marino (2017) found that an attention deficiency hyperactivity disorder (ADHD) influences entrepreneurship 
through the trait of impulsivity that these people possess, so that hyperactivity is positively associated with entrepreneurship. These authors also indicate that sensation seeking, and a lack of premeditation generally have a positive influence on entrepreneurship. The reason is that the uncertainty of the business world produces anxiety, worry, procrastination and inaction in most people (McMullen \& Shepherd, 2006; Paulus, 2007), and thus hyperactivity is a positive feature (Wiklund et al., 2017).

\section{Curiosity}

Curiosity is an innate characteristic of humans that is present in all people, with individual differences in their level of intensity (Berlyne, 1950). It is a desire to acquire new sensory experience and/or knowledge that motivates exploratory behavior (Berlyne, 1954, 1960; Spielberger \& Starr, 1994). Curiosity is motivated by lack of knowledge when we have to make decisions, it is also the will or desire to move forward in the learning process to fill the gap between what we know and what we would like to know (Loewenstein, 1994; Robinson, 2008). Curiosity is considered to be an intrinsic motivation, or what is the same, a state of excitement and satisfaction in which the reward of exploration is to perform the activity itself, instead of simply looking for the desired information (Bougie \& Ichise, 2020; Collins et al., 2004; Zuckerman, 1994).

The concept of curiosity has generally been divided into two broad categories: perceptual curiosity and epistemic curiosity. Perceptual curiosity (PC) is defined as a greater perception and/or reaction to visual, auditory or tactile stimulation (Berlyne, 1954; C. D. Spielberger \& Starr, 1994). Epistemic Curiosity (EC) is the desire for knowledge that motivates people to learn new things, it is what motivates them to seek, obtain and use new knowledge (Berlyne, 1954; Litman et al., 2005; Loewenstein, 1994). Berlyne (1954) describes epistemic curiosity as an impulse to know. Based on this idea, Litman and Spielberger (2003) conceptualize these propositional tendencies as a personality trait associated with positive states of emotional motivation coupled with the intrinsic pleasure of learning. They also indicate that people vary in terms of how often they experience and express it. Epistemic Curiosity comprises two aspects: Diverse Curiosity, which measures the interest in exploring unknown topics to learn something new; and Specific Curiosity, which refers to the enjoyment of solving problems and discovering how things work. This second aspect correlates positively with other measures of curiosity, and is more related to the measures of cognitive activity that measure sensation seeking (Collins et al., 2004; Litman \& Spielberger, 2003).

On the other hand, Litman and Jimerson (2004) indicate that interest (I) and deprivation (D) reflect different types of curiosity that correspond to very different reasons for acquiring new information, in addition to being directed towards different types of learning objectives (Elliot, 1999). Curiosity-I (I-EC) implies the anticipated pleasure of new discoveries and is associated with the acquisition of knowledge simply for the intrinsic joy that it produces (domain-oriented learning). Curiosity-D (D-EC) reduces uncertainty and eliminates undesirable states of ignorance. This dimension is conceptualized as a "need to know", for which the correction, accuracy, and relevance of the desired information of what is unknown is very important (performanceoriented learning). In addition, type D-EC is defined as a state of unmet need. D-EC implies a greater reason for the search for knowledge than type I-EC (Litman, 2005). The reasons behind why people learn predict the degree of effort and persistence they will use in the search for new information as well as the value of the emotional experiences that people have experienced (Estrada, 2020). This is why the relationship between the two types of Curiosity and personal learning objectives are important (Elliot, 1999; Elliot et al., 1999; Elliot \& Church, 1997). We have chosen this model because it has been empirically validated, and we have also found that curiosity has been a little-researched variable in relation to entrepreneurship.

\section{Entrepreneurship Orientation}

According to Zhang and Zhang (2020), entrepreneurs are necessary to ensure economic development, and therefore it is important to know how to identify them. Olson (1985) defines an entrepreneur as a person oriented to the future, capable of taking risks to get involved in the identification and development of new ideas.

In this line, Salinas and Osorio (2012) define entrepreneurship as a set of attitudes and behaviors that give rise to a certain personal profile oriented towards self-confidence, creativity, innovation capacity, sense of responsibility and risk management. So we can say that the important determinants of entrepreneurial behavior are the personality traits that individuals have (Sánchez-García, 2010). It has been found that entrepreneurs have characteristic personality traits that predispose them to acting in an entrepreneurial manner, the most common traits are the Locus of Control, self-efficacy, risk and proactivity (Boada-Grau et al., 2016; Cromie, 2000; Vecchio, 2003).

Tan (2001), in a study conducted with Chinese entrepreneurs, concluded that these entrepreneurs tend to be overly optimistic when they analyze environmental information, especially when they are not familiar with the problem and/or there is great uncertainty. Therefore, if entrepreneurs had a less confidence in their decision-making capacity most new companies would never be launched. Their excess of confidence is what prevents them from feeling overwhelmed by the obstacles that are in their way (Busenitz \& Barney, 1997; Muñoz, 2018). The very nature of entrepreneurship also determines that private entrepreneurs sometimes have to make quick decisions without market research or information (Qazi et al., 2020; Tan, 2010).

We must also take into consideration that culture, public policies and institutions are necessary to develop Entrepre- 
neurial Orientation and business curiosity is positively related to the growth of the company (Jeraj et al., 2015). Therefore, companies and institutions must be receptive towards the enterprising mentality and creativity of individuals. They must also encourage a positive attitude towards innovation and risk in the action of entrepreneurship (Chung \& Gibbons, 1997; Gupta et al., 2018; Nambisan et al., 2018). This is due to the fact that entrepreneurs are a fundamental factor for the economic and social development of countries (Fernández-Laviada \& Rueda, 2011; N. B. Hernández et al., 2018). Putninšs and Sauka (2019), show that constructive risk-taking is the central driver of company performance, mirroring the principle of risk and return in financial investment settings.

\section{Objective and Hypothesis}

The objective of this study is to investigate the moderating role played by (I/D) Curiosity between Impulsivity and Entrepreneurial Orientation and determine whether Curiosity affects the intensity of the relationship between Impulsivity (predictor variable) and Entrepreneurial Orientation (criterion variable). Our review of the literature revealed a gap in this line of research.

The hypotheses of the study are:

Hypothesis 1. Curiosity (I/D EC) plays a moderating role between Impulsivity and Entrepreneurship Orientation (EO).

Hypothesis 2. The relationship between Impulsivity and Entrepreneurship Orientation (EO) is more intense as the level of Curiosity increases.

\section{Method}

\section{Participants}

To collect the data, we made telephone contact with the directors of several companies and agreed on the best time to meet the workers. The participants were 883 Spanish and Colombian employees (49\% male, 51\% female). The mean age was $38.88(S D=12.52)$. The civil status distribution was married or cohabiting $(50.9 \%)$, single (36.8\%), divorced/separated/widowed $(12.3 \%)$. The distribution of the education level was as follows: primary education certificate or less $(1.7 \%)$, lower secondary education or professional training I (11\%), upper secondary education, professional training II or university entrance exams for mature students (43\%), university qualification (44.3\%).

\section{Measures}

\section{Impulsivity}

The Dickman's Impulsivity Inventory Scale (DII; Dickman, 1990), in its Spanish version (Chico et al., 2003), is made up of 23 items and 2 subscales and the response for- mat is dichotomous $(1=$ true / $0=$ false $)$."Factor 1.- Functional Impulsiveness" assesses impulsiveness that is beneficial and that helps us to adapt to unexpected situations that require a quick response. It is made up of 11 items $(\alpha=.77)$ (e.g., "5. Most of the time I can concentrate on my work very quickly"). "Factor 2.- Dysfunctional impulsiveness" refers to impulsiveness that, instead of helping us, can be counterproductive. It is made up of 12 items $(\alpha=.76)$. (e.g., " 2 . I frequently say the first thing that comes into my head without giving it much thought").

\section{Curiosity}

The I/D Curiosity Questionnaire (Litman, 2008), measures the desire for knowledge. It consists of 10 items and 2 subscales: 1 . Curiosity-I (I-EC); (5 items, $\alpha=.82$; example, "2. I find it fascinating to learn new information"). IEC stimulates a positive effect, diverse exploration, learning something completely new and domain-oriented learning. 2 . Curiosity-D (D-EC) (5 items, $\alpha=.76$; example, "8. Conceptual problems keep me awake thinking”). D-EC implies the reduction of uncertainty, specific exploration, the acquisition of information missing from existing knowledge and performance-oriented learning. The response format is a fivepoint Likert scale $(0=$ Almost Never to $4=$ Almost Always).

\section{Entrepreneurial Orientation}

The Entrepreneurial Orientation Scale (Lee et al., 2011) evaluates an individual's orientation towards undertaking a professional or business activity. In its Spanish version (Boada-Grau et al., 2016) it has 12 items and 4 factors, and each factor has 3 items. The factors are: 1.- Autonomy (EOAuto) $(\alpha=.71$; for example, "I don't want any financial support from my parents because I am a grown up now"); 2. Innovativeness (EO-Inno) ( $\alpha=.70$; for example, "I enjoy working on new things, so I am usually up to date with recent trends and current fashions"); 3. Risk Taking (EOAsRi) ( $\alpha=.72$; for example, "I think that starting up a new venture is the only way to succeed in life"); and 4. Competitive Aggressiveness (EO-ComAg) $(\alpha=.70$; for example, "Even if I launch new ventures and fail over and over again, I will keep on trying until I succeed"). The response format was a Likert 1 to 5 scale $(1=$ totally disagree to $5=$ totally agree $)$.

\section{Procedure}

The sample was obtained by non-probabilistic sampling (R. Hernández et al., 2004), also called accidental-random sampling (Kerlinger \& Lee, 2004). The data were collected by making telephone contact with the directors of several companies and agreeing on the best time to meet with their employees. A booklet was made containing all the questionnaires and the instructions for completing them. A psychologist was responsible for collecting the data in each company and for ensuring that no data were lost. The response rate was $83 \%$. 


\section{Statistical analysis}

The data analyses were carried out using the statistical package SPSS 23.0. Reliability was obtained using Cronbach's alpha, while the relationship between Impulsivity, Curiosity and Entrepreneurial Orientation was analyzed with the Pearson correlation coefficient.

A series of multiple hierarchical regression analyses was carried out in steps to examine how Curiosity ( $\mathrm{Z}$ ) was moderated by the relationship between Impulsivity $(X)$ and Entrepreneurial Orientation (Y) (see Cohen \& Cohen, 2003). To calculate this interaction, the independent measures (X, $\mathrm{Z})$ were focused on the average to reduce the problems of multicollinearity (Kleinbaum et al., 1988), and then the interaction (XZ) was calculated. The main predictor variables were focused on the first step and the interaction term in the second step. To establish the importance of the interaction effect, according to Cohen (1992), an increase in explained variance $\left(\Delta R^{2}\right)$ of .02 indicates a good effect size. To interpret the results, a simple effects analysis (simple slope of simple regression equations, Aiken and West, 1991) was used to test the hypothesis that a simple slope differs from zero. Three values were selected: Tertile $1\left(\beta_{\mathrm{H}}\right)$, Tertile $2\left(\beta_{\mathrm{M}}\right)$, and Tertile $3\left(\beta_{\mathrm{L}}\right)$ of the Curiosity.

\section{Results}

\section{Reliability analysis}

All the instruments used showed adequate indices of internal consistency, evaluated using the Cronbach alpha coefficient (Table 1). The minimum value was .71 Innovativeness (EO.Inno) and Competitive Aggressiveness (EO-ComAg), while the maximum value of internal consistency was .91 for Functional Impulsiveness.

Table 1

Descriptive statistics and reliability values with Cronbach's alpha coefficient.

\begin{tabular}{lccccc}
\hline \multicolumn{1}{c}{ Variable } & Minimum & Maximum & Mean & $S D$ & alpha \\
\hline 1. EO-Auto & 3 & 15 & 10.36 & 2.223 & .72 \\
2. EO-Inno & 3 & 15 & 10.75 & 2.453 & .71 \\
3. EO-AsRi & 3 & 15 & 7.98 & 2.662 & .73 \\
4. EO-ComAg & 3 & 15 & 9.32 & 2.551 & .71 \\
5. I-EC & 5 & 20 & 15.09 & 3.360 & .74 \\
6. D-EC & 5 & 20 & 14.97 & 3.191 & .85 \\
7. Imp.F & 2 & 9 & 5.78 & 1.44 & .91 \\
8. Imp.D & 1 & 9 & 5.67 & 1.462 & .87 \\
\hline
\end{tabular}

\section{Correlation analysis}

The results of the correlation analysis are shown in Table 2. The most important results are: (1) All the variables of Entrepreneurial Orientation and Curiosity-I (EO-Auto, EOInno, EO-AsRi, EO-ComAg and I-EC) were positively correlated with all study variables with the exception of Dys- functional Impulsiveness (Imp.D); (2) The D-EC correlates positively with all variables except for the two Impulsivities (Imp.F and Imp.D); (3) Functional Impulsiveness (Imp.F) correlates positively with all variables except Curiosity-D (DEC); (4) Dysfunctional Impulsiveness (Imp.D) only correlates with Functional Impulsiveness (Imp.F).

\section{Table 2}

Correlation between Curiosity (I/D EC), Impulsivity (Imp F/D) and Entrepreneurial Orientation (EO).

\begin{tabular}{lccccccc}
\hline \multicolumn{1}{c}{} & 1 & 2 & 3 & 4 & 5 & 6 & 7 \\
\hline 1. EO-Auto & & & & & & & \\
2. EO-Inno & $.454^{* *}$ & & & & & & \\
3. EO-AsRi & $.313^{* *}$ & $.361^{* *}$ & & & & & \\
4. EO-ComAg & $.399^{* *}$ & $.460^{* *}$ & $.544^{* *}$ & & & & \\
5. I-EC & $.462^{* *}$ & $.472^{* *}$ & $.237^{* *}$ & $.388^{* *}$ & & & \\
6. D-EC & $.261^{* *}$ & $.274^{* *}$ & $.140^{* *}$ & $.279^{* *}$ & $.595^{* *}$ & & \\
7 Imp.F & $.240^{* *}$ & $.228^{* *}$ & $.090^{*}$ & $.133^{* *}$ & $.148^{* *}$ & .033 & \\
8. Imp.D & .074 & -.002 & .054 & .076 & .043 & -.037 & $.274^{* *}$ \\
\hline ** $p<.01 ; * p<.05$ & & & & & & &
\end{tabular}

\section{Analysis of the moderator effect}

The analysis of the moderating effects (Figure 1) is collected in the following analyzes that correspond to the hypotheses to be tested: First, the moderating role of Curiosity (I/D EC) between Impulsivity and Entrepreneurship Orientation (EO) (Hypothesis 1). The results for the moderating effect of Curiosity-I (I-EC) were not confirmed since no moderating effect was observed between Impulsivity and Entrepreneurial Orientation (Table 3). While the results corresponding to the moderating effect of Curiosity-D (D-EC) were only confirmed in the cases of Dysfunctional Impulsivity (Imp.D): EO-Auto $\left(\beta_{\times z}=.104, \Delta R^{2}=.021, p<.01\right)$, EO-Inno $\left(\beta_{x z}=.17, \Delta R^{2}=.028, p<.001\right)$, EO-AsRi $\left(\beta_{x z}=\right.$ $\left..212, \Delta R^{2}=.045, p<.001\right)$ and EO-ComAg $\left(\beta_{x z}=.19, \Delta R^{2}=\right.$ $.036, p<.001)$.

Second, refers to the relationship between Impulsivity and Entrepreneurship Orientation (EO) (Hypothesis 2): this relationship is more intense as Curiosity levels increase. The negative symbol in the interaction coefficients $\left(\beta_{x \times}\right)$ indicates that the intensity of the relationship decreases as the level of Curiosity increases. In our case, the interaction coefficients are positive, which indicates that the intensity increases. The simple effects analysis shows that the slopes are statistically different from zero in high Curiosity values $\left(\beta_{\mathrm{H}}\right)$, in the four dimensions: EO-Auto $\left(\beta_{\mathrm{L}}=.047, \beta_{\mathrm{M}}=.070, \beta_{\mathrm{H}}=.161\right)$, EOInno $\left(\beta_{\mathrm{L}}=.105, \beta_{\mathrm{M}}=.075, \beta_{\mathrm{H}}=.153\right)$, EO-AsRi $\left(\beta_{\mathrm{L}}=.137\right.$, $\left.\beta_{\mathrm{M}}=.129, \beta_{\mathrm{H}}=.305\right), \mathrm{EO}-\operatorname{ComAg}\left(\beta_{\mathrm{L}}=.024, \beta_{\mathrm{M}}=.080, \beta_{\mathrm{H}}=\right.$ .299). Therefore, there is a relationship between Dysfunctional Impulsivity (Imp.D) and Entrepreneurial Orientation (EO) when workers have a high Curiosity-D (D-EC) level. However, the relationship disappears when the D-EC levels are medium and low in all dimensions. 
Table 3

Analysis of the moderator effect of Curiosity (I/D EC) between Impulsivity (Imp F/D) and Entrepreneurial orientation (EO) $(N=883)$.

\begin{tabular}{|c|c|c|c|c|c|c|c|c|}
\hline & \multicolumn{5}{|c|}{ Hierarchical multiple regression } & \multirow{2}{*}{\multicolumn{3}{|c|}{ Simple effects }} \\
\hline & \multicolumn{3}{|c|}{ Step 1} & \multicolumn{2}{|c|}{ Step 2} & & & \\
\hline & $\beta_{\mathrm{x}}$ & $\beta_{z}$ & $\mathrm{R}^{2}$ & $\beta_{\mathrm{xz}}$ & $\Delta R^{2}$ & $\beta_{\mathrm{L}}$ & $\beta_{\mathrm{M}}$ & $\beta_{\mathrm{H}}$ \\
\hline \multicolumn{9}{|l|}{$\overline{\text { EO-Auto }}$} \\
\hline \multicolumn{9}{|l|}{$I-E C$} \\
\hline $\operatorname{Imp.F}$ & $.175^{* * *}$ & $.436^{* * *}$ & $.241 * * *$ & -.012 & .000 & $.291 * * *$ & .037 & $.233 * * *$ \\
\hline $\operatorname{Imp} \cdot D$ & .054 & $.460 * * *$ & $.213^{* * *}$ & .070 & .005 & .050 & .157 & .064 \\
\hline \multicolumn{9}{|l|}{$D-E C$} \\
\hline $\operatorname{Imp.F}$ & $.232 * * *$ & $.254^{* * *}$ & $.118^{* * *}$ & $.099 *$ & $.010^{*}$ & $.174 * *$ & $.238^{* *}$ & $.355^{* * *}$ \\
\hline $\operatorname{Imp} \cdot D$ & .084 & $.265^{* * *}$ & $.071 * * *$ & $.104 *$ & $.021 * *$ & .047 & .070 & $.161 *$ \\
\hline \multicolumn{9}{|l|}{ EO-Inno } \\
\hline \multicolumn{9}{|l|}{$I-E C$} \\
\hline $\operatorname{Imp.F}$ & $.162 * * *$ & $.448^{* * *}$ & $.245^{* * *}$ & .055 & .003 & .147 & .043 & $.331 * * *$ \\
\hline Imp.D & -.022 & $.473^{* * *}$ & $.220^{* * *}$ & $.111^{* *}$ & $.012^{* *}$ & $.183^{*}$ & .041 & .074 \\
\hline \multicolumn{9}{|l|}{$D-E C$} \\
\hline $\operatorname{Imp.F}$ & $.219 * * *$ & $.266^{* * *}$ & $.119 * * *$ & .075 & .006 & $.176^{*}$ & $.261^{*}$ & $.294 * *$ \\
\hline $\operatorname{Imp} \cdot D$ & .008 & $.274 * * *$ & $.071 * * *$ & $.170^{* * *}$ & $.028^{* * *}$ & .105 & .075 & $.153^{*}$ \\
\hline \multicolumn{9}{|l|}{ EO-AsRi } \\
\hline \multicolumn{9}{|l|}{$I-E C$} \\
\hline Imp.F & .056 & $.229 * * *$ & $.059 * * *$ & .027 & .001 & .037 & .045 & .085 \\
\hline Imp.D & .044 & $.235^{* * *}$ & $.054 * * *$ & $.130^{* *}$ & $.016^{* *}$ & $.165^{*}$ & .151 & .130 \\
\hline \multicolumn{9}{|l|}{$D-E C$} \\
\hline $\operatorname{Imp.F}$ & .086 & $.037 * *$ & $.023^{* * *}$ & $.100^{*}$ & $.010^{*}$ & .003 & $.165^{*}$ & .113 \\
\hline $\operatorname{Imp} . D$ & .059 & $.142^{* *}$ & $.019^{* *}$ & $.212^{* * *}$ & $.045^{* * *}$ & .137 & .129 & $.305^{* * *}$ \\
\hline \multicolumn{9}{|c|}{ EO-ComAg } \\
\hline \multicolumn{9}{|l|}{$I-E C$} \\
\hline Imp.F & .077 & $.377 * * *$ & $.153^{* * *}$ & .028 & .001 & .070 & .048 & .131 \\
\hline $\operatorname{Imp} . D$ & .060 & $.386^{* * *}$ & $.151 * * *$ & $.126^{* *}$ & $.016^{* *}$ & .111 & .074 & $.181 * *$ \\
\hline \multicolumn{9}{|l|}{$D-E C$} \\
\hline $\operatorname{Imp.F}$ & $.124^{* *}$ & $.275^{* * *}$ & $.089 * * *$ & .024 & .001 & .135 & $.209 * *$ & .044 \\
\hline $\operatorname{Imp} . D$ & .087 & $.282^{* * *}$ & $.081 * * *$ & $.190^{* * *}$ & $.036 * * *$ & .024 & .080 & $.299 * * *$ \\
\hline
\end{tabular}

\section{Figure 1}

Representation of a bypothetical model of the moderating and mediating variables of the relationship Impulsivity-entrepreneurial orientation.

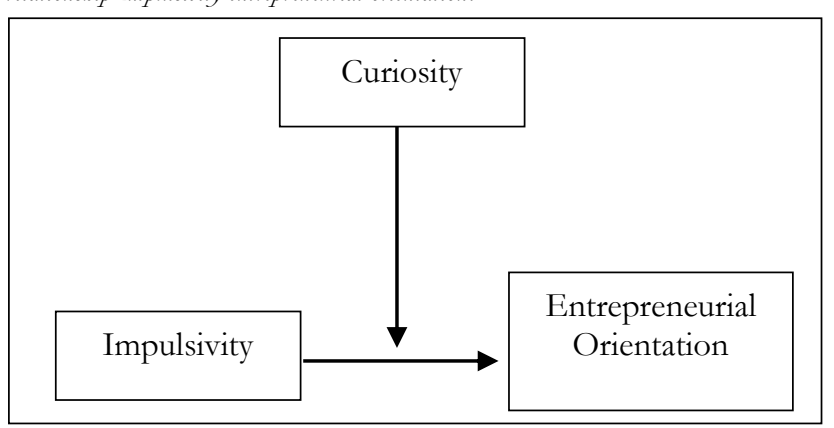

\section{Discussion}

The main objective of this study was to investigate the possible moderating role of the variables of Curiosity between Impulsivity and Entrepreneurship Orientation. The first hypothesis proposed in the research refers to the correlations between the dimensions of Impulsivity and Entrepreneurship Orientation. Its objective is to verify whether the two types of Curiosity (Interest/Deprivation) affect the intensity of the relationship between Impulsivity (predictive variable) and Entrepreneurship Orientation (criterion variable).

That is, the objective was to determine whether, considering that Impulsivity affects Entrepreneurial Orientation, people with high levels of Curiosity tend to show greater Entrepreneurial Orientation. Hypothesis 1 is partially confirmed, since the results obtained confirm that Curiosity-D has a significant moderating effect on Dysfunctional Impulsivity and its relationship with Entrepreneurship in all the dimensions taken into consideration in the present research (Eo- Auto, EO-Inno, EO-AsRi and EO-ComAg). Hypothesis 2 partially confirms that the intensity of the relationship between Dysfunctional Impulsivity and Entrepreneurial Orientation increases as the levels of Curiosity-D increase. Curiosity-I did not have a moderating effect on the relationship between Impulsivity and Entrepreneurial Orientation. Therefore, there is a relationship between Dysfunctional Impulsivity (Imp.D) and Entrepreneurship Orientation (EO) when workers have a high level of Curiosity-D (D-EC); however, the relationship disappears when the D-EC levels are medium and low in all dimensions.

The results of this research show that the type of Curios- 
ity that behaves as a moderator is Curiosity in cases of Deprivation, or Curiosity- $\mathrm{D}$, since it moderates the relationship between Dysfunctional Impulsivity and Entrepreneurial Orientation. Thus, Impulsivity as a tendency to act with little foresight (Dickman, 1990, 1993, 2000), Dysfunctional Impulsivity, which in other contexts is a source of problems, in combination with Curiosity-D is transformed into a trait that favors Entrepreneurial Orientation.

In the same way that it has been found that hyperactivity, sensation seeking and lack of premeditation are positively associated with the entrepreneurship spirit (Wiklund et al., 2017), we must bear in mind that the characteristics of the business world produce inaction in most people (McMullen \& Shepherd, 2006; Paulus, 2007) so the traits associated with hyperactivity are a positive feature (Wiklund et al., 2017). This result is very relevant when enterprising people are selected, in addition to the fact that entrepreneurs are necessary to ensure economic development, which is why, according to Sánchez (2010), it is important to know how to identify them.

\section{Conclusion}

The present study contributes to our knowledge about how curiosity acts as a moderating variable between Impulsivity

\section{References}

Aiken, L. S., \& West, S. (1991). Multiple regression: Testing and interpreting interactions. Sage.

Aljanabi, A. R. A. (2018). The mediating role of absorptive capacity on the relationship between entrepreneurial orientation and technological innovation capabilities. International Journal of Entrepreneurial Bebavior \& Research, 24, 818-841. https://doi.org/10.1108/IJEBR-07-2017-0233

Berlyne, D. E. (1950). Novelty and curiosity as determinants of exploratory behaviour. British Journal of Psychology. General Section, 41, 68-80. https://doi.org/10.1111/j.2044-8295.1950.tb00262.x

Berlyne, D. E. (1954). A theory of human curiosity. British Journal of Psychology. General Section, 45, 180-191. https://doi.org/10.1111/j.20448295.1954.tb01243.x

Boada-Grau, J., Sánchez-García, J. C., Viardot, E., Boada-Cuerva, M., \& Vigil-Colet, A. (2016). Adaptation of an entrepreneurial motivation scale into Spanish. Anales de Psicología, 32, 571-577. https://doi.org/10.6018/analesps.32.2.208381

Bolton, D. L. (2012). Individual entrepreneurial orientation: Further investigation of a measurement instrument. Academy of Entrepreneurship Journal, 18, 91. https://doi.org/10.1108/00400911211210314

Bougie, N., \& Ichise, R. (2020). Skill-based curiosity for intrinsically motivated reinforcement learning. Machine Learning, 109(3), 493-512. https://doi.org/10.1007/s10994-019-05845-8

Busenitz, L. W., \& Barney, J. B. (1997). Differences between entrepreneurs and managers in large organizations: Biases and heuristics in strategic decision-making. Journal of Business Venturing, 12, 9-30. https://doi.org/10.1016/S0883-9026(96)00003-1

Chico, E., Tous, J. M., Lorenzo-Seva, U., \& Vigil-Colet, A. (2003). Spanish adaptation of Dickman's impulsivity inventory: Its relationship to Eysenck's personality questionnaire. Personality and Individual Differences, 35, 1883-1892. https://doi.org/10.1016/S0191-8869(03)00037-0

Chung, L. H., \& Gibbons, P. T. (1997). Corporate Entrepreneurship: The roles of ideology and social capital. Group and Organization Management, 22, 10-30. https://doi.org/10.1177/1059601197221004

Cohen, J. (1992). A power primer. Psychological Bulletin, 112, 155-159. and Entrepreneurial Orientation. In conclusion, the results of this research show that the type of Curiosity that behaves as a moderator is Curiosity in cases of Deprivation, or Curiosity-D since it moderates the relationship between Dysfunctional Impulsivity and Entrepreneurial Orientation. Finding us that Impulsivity as a tendency to act with little foresight (Dysfunctional Impulsivity), which in other contexts is a source of problems, in combination with Curiosity$\mathrm{D}$ is transformed into a feature that favors Entrepreneurial Orientation.

The present research shows us that those people who, besides having a high score in Dysfunctional Impulsivity, have high levels of Curiosity in cases of Deprivation will be those able to obtain greater success as entrepreneurs. This is in line with what Robinson (2008) indicated, that entrepreneurs need to be curious, challenged and able to adapt to change, which drives them to seek new opportunities.

This research has some limitations, the data obtained comes from self-reports that the participants completed, so that part of the conclusions may be affected by the variation of the common method. In addition to its design is transversal, which means that the results cannot be interpreted causally.

Cohen, J. (2003). Applied multiple regression/correlation analysis for the behavioral sciences (3rd ed.). L. Erlbaum Associates.

Collins, R. P., Litman, J. A., \& Spielberger, C. D. (2004). The measurement of perceptual curiosity. Personality and Individual Differences, 36, 11271141. https://doi.org/10.1016/S0191-8869(03)00205-8

Cromie, S. (2000). Assessing entrepreneurial inclinations: Some approaches and empirical evidence. European Journal of Work and Organizational Psychology, 9, 7-30. https://doi.org/10.1080/135943200398030

Dickman, S. J. (1990). Functional and dysfunctional impulsivity: Personality and cognitive correlates. Journal of Personality and Social Psychology, 58(1), 95-102. https://doi.org/10.1037/0022-3514.58.1.95

Dickman, S. J. (1993). Impulsivity and Information Processing. In The Impulsive Client: Theory, Research, and Treatment (pp. 151-184). American Psychological Association. https://doi.org/10.1037/10500-010

Dickman, S. J. (2000). Impulsivity, arousal and attention. Personality and Individual Differences, 28, 563-581. https://doi.org/10.1016/S01918869(99)00120-8

Elliot, A. J. (1999). Approach and avoidance motivation and achievement goals. Educational Psychologist, 34, 169-189. https://doi.org/10.1207/s15326985ep3403_3

Elliot, A. J., \& Church, M. A. (1997). A hierarchical model of approach and avoidance achievement motivation. Journal of Personality and Social Psychology, 72, 218-232. https://doi.org/10.1037/0022-3514.72.1.218

Elliot, A. J., McGregor, H. A., \& Gable, S. (1999). Achievement goals, study strategies, and exam performance: A mediational analysis. Journal of Educational Psychology, 91, 549-563. https://doi.org/10.1037/00220663.91.3.549

Estrada, A. (2020). Is the curiosity trait a key to entrepreneurial mindset? Université de Liège, Liège, Belgique.

Fernández-Laviada, A., \& Rueda, M. (2011). La actitud emprendedora: una década de investigacion y análisis de los estudiantes de la Facultad de Ciencias Económicas y Empresariales de la Universidad de Cantabria [The entrepreneurial attitude: a decade of research and analysis of the students of the Faculty of Economic and Business Sciences of the 
University of Cantabria]. In 1 er encuentro internacional AECA en America latina.

Fillis, I., \& Rentschler, R. (2010). The role of creativity in entrepreneurship. Journal of Enterprising Culture, 18, 49-81. https://doi.org/10.1142/S0218495810000501

Gupta, D. R., Veliyath, R., \& George, R. (2018). Influence of national culture on IPO activity. Journal of Business Research, 90, 226-246. https://doi.org/10.1016/j.jbusres.2018.04.023

Hernández, N. B., Intriago, R. V. G., Espinoza, J. C. G., \& Vásconez, P. J. D. (2018). Competencia de emprendimiento como sustento de la formación integral e inserción social del estudiante [Entrepreneurship competence as support for the comprehensive training and social insertion of the student]. Revista Orbita Pedagógica., 4, 9-12.

Hernández, R., Fernández, C., \& Baptista, P. (2004). Metodología de la Investigación [Investigation methodology]. McGraw-Hill Interamericana.

Jeraj, M., Maric, M., Todorovic, I., \& Cudanov, M. (2015). The Role of Openness and Entrepreneurial Curiosity in Company's Growth. Amfiteatru Economic Journal, 17, 371-389.

Kerlinger, F. N., \& Lee, H. B. (2004). Behavior Research. Research methods in social sciences. McGraw-Hill.

Kleinbaum, D. G., Kupper, L. L., \& Muller, K. (1988). Applied regression analysis and other multivariate methods. PWS-Kent.

Lee, S. M., Lim, S., \& Pathak, R. D. (2011). Culture and entrepreneurial orientation: a multi-country study. International Entrepreneurship and Management Journal, 7, 1-15. https://doi.org/10.1007/s11365-009-01174

Litman, J. A. (2005). Curiosity and the pleasures of learning: Wanting and liking new information. Cognition \& Emotion, 19, 793-814. https://doi.org/10.1080/02699930541000101

Litman, J. A. (2008). Interest and deprivation factors of epistemic curiosity. Personality and Individual Differences, 44, 1585-1595. https://doi.org/10.1016/j.paid.2008.01.014

Litman, J. A., Hutchins, T., \& Russon, R. (2005). Epistemic curiosity, feeling-of-knowing, and exploratory behaviour. Cognition \& Emotion, 19, 559-582. https://doi.org/10.1080/02699930441000427

Litman, J. A., \& Jimerson, T. L. (2004). The Measurement of Curiosity As a Feeling of Deprivation. Journal of Personality Assessment, 82, 147-157. https://doi.org/10.1207/s15327752jpa8202_3

Litman, J. A., \& Spielberger, C. D. (2003). Measuring Epistemic Curiosity and Its Diversive and Specific Components. Journal of Personality Assessment, 80, 75-86. https://doi.org/10.1207/S15327752JPA8001_16

Loewenstein, G. (1994). The psychology of curiosity: A review and reinterpretation. Psychological Bulletin, 116, 75-98. https://doi.org/10.1037/0033-2909.116.1.75

McMullen, J. S., \& Shepherd, D. A. (2006). Entrepreneurial Action And The Role Of Uncertainty In The Theory Of The Entrepreneur. Academy of Management Review, 31, 132-152. https://doi.org/10.5465/amr.2006.19379628

Muñoz, P. (2018). A cognitive map of sustainable decision-making in entrepreneurship: A configurational approach. International Journal of Entrepreneurial Behaviour and Research, 24(3), 787-813. https://doi.org/10.1108/IJEBR-03-2017-0110

Nambisan, S., Siegel, D., \& Kenney, M. (2018). On open innovation, platforms, and entrepreneurship. Strategic Entrepreneurship Journal, 12(3), 354-368. https://doi.org/10.1002/sej.1300

Olson, P. D. (1985). Entrepreneurship: Process and Abilities. American Journal of Small Business, 10, 25-31. https://doi.org/10.1177/104225878501000103

Paulus, M. P. (2007). Decision-Making Dysfunctions in Psychiatry Altered Homeostatic Processing? Science, 318, 602-606. https://doi.org/10.1126/science.1142997
Putniņš, T. J., \& Sauka, A. (2019). Why does entrepreneurial orientation affect company performance? Strategic Entrepreneurship Journal, 14(4), 711-735. https://doi.org/10.1002/sej.1325

Qazi, W., Qureshi, J. A., Raza, S. A., Khan, K. A., \& Qureshi, M. A. (2020) Impact of personality traits and university green entrepreneurial support on students' green entrepreneurial intentions: the moderating role of environmental values. Journal of Applied Research in Higher Education. https://doi.org/10.1108/JARHE-05-2020-0130

Rauch, A., Wiklund, J., Lumpkin, G. T., \& Frese, M. (2009). Entrepreneurial Orientation and Business Performance: An Assessment of Pas Research and Suggestions for the Future. Entrepreneurship Theory and Practice, 33, 761-787. https://doi.org/10.1111/j.1540$6520.2009 .00308 . x$

Robinson, D. A. (2008). Keeping pace with change in SMEs: creating and maintaining congruence and consistency in SMEs in transition economies. International Journal of Entrepreneurship and Innovation Management, 8, 272-285. https://doi.org/10.1504/IJEIM.2008.019530

Robinson, S., \& Stubberud, H. A. (2014). Elements of entrepreneurial orientation and their relationship to entrepreneurial intent. Journal of Entrepreneurship Education, 17, 1-11.

Salinas, F., \& Osorio, L. (2012). Emprendimiento y Economía Social, oportunidades y efectos en una sociedad en transformación [Entrepreneurship and Social Economy, opportunities and effects in society in transformation]. CIRIEC-España, Revista de Economía Pública, Social y Cooperativa, 75, 129-151. https://doi.org/0213-8093

Sánchez-García, J. C. (2010). Evaluación de la personalidad emprendedora: Validez factorial del cuestionario de orientación emprendedora (COE) [Evaluation of the entrepreneurial personality: Factorial validity of the entrepreneurial orientation questionnaire]. Revista Latinoamericana de Psicologia, 42, 41-52. http://www.redalyc.org/html/805/80515880004/

Spielberger, C. D., \& Starr, L. M. (1994). Curiosity and exploratory behavior. In Motivation: Theory and research (pp. 221-243). McGraw-Hil Book Company. https://doi.org/10.1037/11164-000

Spielberger, Charles D., \& Starr, L. (1994). Curiosity and exploratory behavior. In H. F. O’Neil \& M. Drillings (Eds.), Motivation: theory and research (pp. 221-243). Lawrence Earlbaum Associates, Inc.

Tan, J. (2001). Innovation and risk-taking in a transitional economy: A comparative study of chinese managers and entrepreneurs. Journal of Business Venturing, 16, 359-376. https://doi.org/10.1016/S08839026(99)00056-7

Tan, J. (2010). Regulatory Environment and Strategic Orientations in a Transitional Economy: A Study of Chinese Private Enterprise. In SSRN (Vol. 21, Issue 1). SAGE PublicationsSage CA: Los Angeles, CA. https://doi.org/10.2139/ssrn.1552141

Vecchio, R. P. (2003). Entrepreneurship and leadership: Common trend and common threads. In Human Resource Management Review (Vol. 13, Issue 2, pp. 303-327). JAI. https://doi.org/10.1016/S1053 4822(03)00019-6

Wiklund, J., Yu, W., Tucker, R., \& Marino, L. D. (2017). ADHD, Impulsivity and Entrepreneurship. Journal of Business Venturing, 32, $627-$ 656. https://doi.org/10.1016/J.JBUSVENT.2017.07.002

Wismans, A., Thurik, R., Verheul, I., Torrès, O., \& Kamei, K. (2020). Attention-Deficit Hyperactivity Disorder Symptoms and Entrepreneurial Orientation: A Replication Note. Applied Psychology, 69(3), 1093-1112. https://doi.org/10.1111/apps.12247

Zhang, W., \& Zhang, W. (2020). Entrepreneurs and Capitalists in the Market. In Ideas for China's Future (pp. 67-81). Springer Singapore. https://doi.org/10.1007/978-981-15-4304-3_8

Zuckerman, M. (1994). Behavioral expressions and biosocial bases of sensation seeking. Cambridge University Press. 